\section{Conspicuous Consumption and its Relation to Brand Consciousness, Status Consumption and Self-Expression}

\author{
Bruno Medeiros Assimos ${ }^{1,+}$ (D) \\ ${ }^{1}$ Pontifícia Universidade Católica de Minas Gerais, Belo Horizonte, MG, Brazil \\ Marcelo de Rezende Pinto ${ }^{2, \Omega}$ (D) \\ ${ }^{2}$ Pontifícia Universidade Católica de Minas Gerais, Belo Horizonte, MG, Brazil \\ Ramon Silva Leite ${ }^{3, \pm}$ (D) \\ ${ }^{3}$ Pontifícia Universidade Católica de Minas Gerais, Belo Horizonte, MG, Brazil \\ Matheus Lemos de Andrade ${ }^{4, *(1)}$ \\ ${ }^{4}$ Pontifícia Universidade Católica de Minas Gerais, Belo Horizonte, MG, Brazil
}

\begin{abstract}
This paper presents and discusses the results of an empirical research whose objective was to discuss the relationship between the concepts of conspicuous consumption, status consumption and self-expression. For this, we have used the model proposed by Mann and Sahni (2015), which suggests the existence of three fundamental dimensions in the explanation of conspicuous consumption, setting the discussion under the aegis of lifestyle, brand consciousness, consumption of status and self-expression. An online survey was implemented, which generated a database composed of 398 respondents who had attended a marriage ceremony in the last six months. For data analysis, the modeling of structural equations using the PLS approach was used. The results of the study suggest, among other findings, that there is a relatively strong association between the constructs status consumption and self-expression, it was also possible to verify a significant and positive influence between the dimensions of the construct conspicuous consumption with status consumption. In addition, we found that there is a strong influence between social conformity and status consumption and between status consumption and self-expression. Thus, the article contributes to the studies of consumption by advancing the discussion about the antecedents and consequences of conspicuous consumption and the relationship between conspicuity and status.
\end{abstract}

Keywords: Conspicuous consumption; Status consumption; Self-expression; Wedding Ceremony.

\section{INTRODUCTION}

In the last decades, the study of consumption has gained broader and wider contours within social sciences researchers since the 1980s focused on considering it as secondary and peripheral in the study of societies. Curiously enough, some scholars came, well before this period, to raise some questions involving the characteristics of consumption eminently linked to status and conspicuity. Among these authors, it is possible to cite Veblen (1988) and Simmel (1957). It was Veblen (1988), who had his work published at the end of the nineteenth century, coining the term conspicuous consumption as a way of demonstrating status. An attempt is made to relate the two concepts in 
the author's work. Simmel (1957) defends the idea that individuals, in search of a social ascent, imitate the consumption patterns of the upper classes.

After more than a hundred years after the seminal works of these two authors, although other researchers have already made efforts to understand the remarkable elements related to the concepts of conspicuous consumption and status consumption (Mason, 1984; Page, 1992; Marcoux, Filiatrault, \& Cheron, 1997; O'Cass \& McEwen, 2004), two points should be emphasized. With conspicuous consumption and, mainly, its relation with other concepts dear to the understanding of consumption still being central points for consumer research, because, according to McCracken (1987, p. 150), "conspicuous and competitive consumption are especially important to the study of the history of consumption because they play such an important role in the growth of a consumer society". In addition, it is possible to perceive gaps in the literature articulating these concepts. Among these shortcomings, some issues emerge that deserve further scrutiny by researchers of consumer behavior. Among them, it is possible to list the following: What is the relationship between lifestyle and brand consciousness? To what extent is conspicuous consumption influenced by brand consciousness? What is the relationship between conspicuous consumption and status consumption? How is self-expression related to conspicuous consumption and status consumption? In other words, even if these concepts seem interconnected, one must not question the extent to which each one interferes and/or influences the others.

It is precisely within the scope of these inquiries and in the gaps created by them that the interest in conducting an empirical research with the objective of discussing the relationship between the concepts of Conspicuous Consumption, Status Consumption and Self-Expression arises, as well as to verify how the construct Lifestyle may be associated with conspicuous consumption and self-expression. Thus, we should mention that the article proposes to bring a theoretical contribution to the understanding of the concept of conspicuous consumption by testing the establishment of interlocutions, in the form of antecedents and consequent, with the constructs already mentioned. For this purpose, when searching the literature, we come to the model proposed by Mann and Sahni (2015) that sought to establish these relationships. This model suggests the existence of four fundamental dimensions in the explanation of conspicuous consumption, setting the discussion under the aegis of Lifestyle, Brand Consciousness (antecedents), Consumption of Status and Selfexpression (consequential).

To empirically test these relationships, also following the work by Mann and Sahni (2015) we deem it appropriate to choose an occasion in which the notions of status and conspicuity display were made explicit. As also used in the work by Carvalho and Pereira (2013), we chose to consider respondents who had attended a marriage ceremony in the last six months. This context seems to offer elements that serve to work the concepts of lifestyle, use of brands, conspicuous consumption and status consumption. It is worth considering that the market for parties and ceremonies, according to the Brazilian Association of Social Events (Abrafesta, 2018), has remained stable since the year 2014 with revenues estimated at almost 17 billion in 2016. It should also be mentioned that marriages already exceed the one million mark per year in Brazil.

The execution of the work is justified by some reasons. Firstly, as previously mentioned, there are questions about the antecedents of status consumption, as well as discussions and empirical works that seek to relate the concepts of status consumption and conspicuous consumption. It should be mentioned that both concepts are central to the study of consumption and to understand the relation between them can be revealing to the understanding of fundamental issues linked to consumer society. Although it is important to emphasize that the paper intends to go beyond the replication of the model proposed by Mann and Sahni (2015), one cannot fail to mention that, in such different cultural contexts, the mere replication of a model would serve to provide insights and issues that would 
BBR

16,4

motivate interesting discussions on the issues involved. Second, although there are studies that discuss the concepts of conspicuous consumption mainly in a historical perspective (McCracken, 1987; Mason, 2002), the paper seeks to fill a gap in consumer literature regarding the better understanding of consumption conspicuous with its antecedents and consequent in a particular cultural context. Thirdly, it is possible to point out that, empirically, these relations were not explored in the marketing literature in Brazil, especially when one considers the context of marriage ceremonies. This event is steeped in diverse symbolism ranging from the choice of sumptuous venues, party organizing, rites of passage, hiring of various professionals, to the tradition of gift giving, not to mention wedding travel. It is also an opportunity to meet family and friends. All of this causes families to spend large amount of money, time and energy on their achievement. In this way, it is possible to perceive, in this celebration, characteristics that seem to have great adherence to access concepts related to status and conspicuity.

We organized the article in five other sections, in addition to the introduction. The first one has the objective of briefly discussing the important concepts that make up the conceptual model of the research and the proposition of its hypotheses. Then, we included a methodology section to present the details of the procedures adopted in empirical research. The presentation section of the results was also contemplated, which opens space for the discussion of the results, where we seek to deepen the analysis. Finally, the conclusions section has the function of presenting final comments of the study, as well as pointing out the limitations and possible opportunities of future studies involving the themes.

\section{REVIEW OF THE LITERATURE, RESEARCH HYPOTH- ESES AND CONCEPTUAL MODEL}

\subsection{A BRIEF REVIEW OF THE LITERATURE}

The themes of fashion and consumption dominate the modern psyche strongly and are linked to the current social and cultural conditions, shaping the central contexts where the various decisions about consumption are daily taken (O'Cass \& McEwen, 2004). The social aspect of consumption imbues it with symbolism that is often generated locally, regionally, or even globally (Shukla, 2010). The symbolism that is deposited in certain goods and services denote direct meanings to those who acquire them, possess them, use them and exhibit them, transforming them into true enhancers of messages that one wishes to convey (Belk, 1988).

The term "status consumption" appropriately reflects this association. The expression of the status of the owner through his habits of consumption was quickly connected to the idea of conspicuous consumption by Veblen in 1899. In formulating the idea of conspicuous consumption the author understood consumption as an activity motivated by social aspirations by recognizing signs of status among other consumers. When it comes to social consumption, the group plays a preponderant role. Participation in groups is psychologically satisfactory for human beings, with the tendency to imitate members with the aim of being accepted as part of it. However, simple participation is not enough, the desire for distinction and recognition of the individual within the group is also present (O'Cass \& Frost, 2002).

For Eastman, Goldsmith and Flynn (1999), the consumption of status does not necessarily involve the public display of wealth, its connection with the sense of ownership is much greater. However, this type of consumption also seeks to increase the prestige and wellbeing of its consumer (O'Cass \& McEwen, 2004). The consumption of status products can 
help people in the pursuit of self-respect and social approval (Eastman et al., 1999). Status consumption occurs independently of social class and is measured by the social advantage that the purchase offers (Mason, 2002), with events and special occasions being a great opportunity to use products that express it (Belk, 1988; Shukla, 2010). The consumption of status brings social esteem and provides socio-psychological advantages to the individual in a social network (Shukla, 2010), its acquisition is one of the strongest measures of social success (O'Cass \& Frost, 2002).

Before we enter into the concept of conspicuous consumption it is interesting to note that many authors draw attention to the existing confusion about the terms conspicuous consumption and consumption of status, often treated as equals in the literature. The first attempt to understand these concepts rests with Veblen (1994), who considered both as a form of ostentatious consumption, carried out with the purpose of demonstrating the social condition. Veblen's "novelty" in his work lies in the fact that it amplifies or shifts the focus of the way of understanding the purpose of acquisition and accumulation of goods in addition to the economically legitimate objective of acquisition, which the economic theory should account for. He conceives consumption as meeting both the physical needs of the consumer and their higher, spiritual, aesthetic, intellectual, or other needs. Another interesting fact is the assertion that the pattern of spending accepted by the community or by the class to which the individual belongs determines largely their standard of living. The consumer motive is a desire to conform to established usage, to avoid unfavorable comments and to live according to the accepted rules of decency in the quality, quantity and degree of goods consumed, as well as in the worthy employment of their time and effort (Veblen, 1994).

In this context, it is worth considering that conspicuous consumption should be seen as a way to increase prestige before society, through the public display of wealth. Its concept involves the exhibition and ostentation, which requires the presence of others (O'Cass \& McEwen, 2004). These authors end up updating the concept and define conspicuous consumption as the tendency of individuals to improve their image through the conspicuous consumption of possessions that communicate certain social statuses. This type of consumption is so strong as a driver of personal visibility that it is present even in poor countries, where people often engage in this type of consumption before they even meet other vital needs (Belk, 1988).

One issue that may arise in this discussion has to do with the difference between the concepts of consumption of status and conspicuous consumption. Although the relation between them is evident, it is important to emphasize that conspicuous consumption emphasizes the public exhibition of the goods, while the consumption of status focuses a little more on the possession of the goods that function as markers of social status. Conspicuous consumption, therefore, is somewhat more related to the public image of consumers, that is, in the explicit communication of the products that it exhibits in its social groups.

Equally important is the claim that conspicuous consumption has incorporated dimensions related to three dimensions: ostentation and signaling (Bagwell \& Bernheim, 1996; Amaldoss \& Jain, 2005); uniqueness (Corneo \& Jeanne, 1997) and social conformity (Miller, Mcintyre, \& Mantrala, 1993). Ostentation and signage indicate that consumption in public contexts causes the impression of the social position to be sought through exclusive and expensive products. Uniqueness means distinction through the rarity of ownership. Consumers acquire brands that are associated with wealth and status, and provide a selfimage distinct from themselves. Social conformity implies action in accordance with the expectations of the group or the surpassing of them, including brands that receive symbolism valued in the group (Mann \& Sahni, 2015).

Self-expression encompasses signals to others of an external identity and personal preferences. It is used as a vehicle to convey the supremacy of personal uniqueness and social 
BBR

16,4

groups through the purchase of branded products (Mann \& Sahni, 2015). The purchase of high quality products, high prices and sufficiently positive social effects are revealed as the target of the desire of those who express themselves strongly for the products they acquire, even if the literature does not make a significant correlation of this phenomenon with social class (Amaldoss \& Jain, 2005). It is precisely in self-expression that the brand creates potential sentimental benefits for consumers (Shukla, 2010).

Thus, it is noted that self-expression is a kind of mechanism that gives conditions for the manifestation of conspicuous consumption behaviors. If there is no possibility of expressing themselves through products and consumption, the public display of products (conspicuous consumption) would no longer be related to social aspects and would probably equate to behaviors guided exclusively by economic-utilitarian assumptions.

Other constructs, however, seem to be related in this discussion: lifestyle and brand consciousness. Lifestyle reveals how someone conducts their life in relation to their consumption habits, pointing out their preferences and their use of time and money. For Mann and Sahni (2015) two other subcategories act in the formation of lifestyle, unique lifestyle and centrality of the lifestyle. The unique lifestyle means engaging in special activities that provoke the impression of living an incomparable and unique way of life (Mann \& Sahni, 2015). The centrality of lifestyle encompasses how present this way of life is in one's daily life. Thus, an individual would perform all of his or her plans around the activities that make up his unique lifestyle, prioritizing him. The activity of purchasing branded products can be considered as a way of life and the planning of the individual's activities can guide this activity, taking it as central to their lifestyle (Mann \& Sahni, 2015). The importance of involvement in certain shopping activities, for example, can guide the planning of an individual's vacation or their free time, or even their priority in relation to work or other social spheres.

Brand consciousness refers to the trend of buying expensive and well-known brands. Social influence is present in the sense that the group provides the social references of brands and products that promote the acceptance of the individual, pressing the subject for social norms and depositing their expectations through socializing institutions such as family, hobby groups, work groups, among others (Leigh \& Gabel, 1992). Here, brand consciousness takes its place in the group, is validated and reinforced with its symbolisms that may contain several discourses (Belk, 1988). To use it means to reinforce the brand's own discourse in itself. For O'Cass and McEwen (2004), brands are seen as important in creating an identity, a sense of accomplishment and identification for consumers, as they have the ability to convey messages and determine how consumers themselves are perceived by others (Belk, 1978; Solomon, 1983).

The major question that arises here is that, in view of all the definitions presented, there are many questions that end up reinforcing the thesis (enunciated in the introductory section of this article) that all these concepts seem to be interconnected, but it is pertinent to verify how each one interferes and/or influences the others. In this sense, the next section presents the conceptual model that will guide empirical research.

\subsection{CONCEPTUAL MODEL}

From the theoretical discussions presented previously and in view of the study of Mann and Sahni (2015), we reached the conceptual model of the research presented in Figure 1, which presents five constructs. The first of them - Lifestyle - was operationalized through the dimensions of Individual Lifestyle and Centrality of Lifestyle. The second is called Brand Consciousness. The third construct contemplated is the one corresponding to the Conspicuous Consumption that, according to the literature, can be dismembered in the dimensions Ostentation and Signage, Uniqueness and Social Conformity. The fourth construct is the Status Consumption. Finally, the fifth construct is the so-called Self-expression. 
Figure 1 - Conceptual model Lifestyle

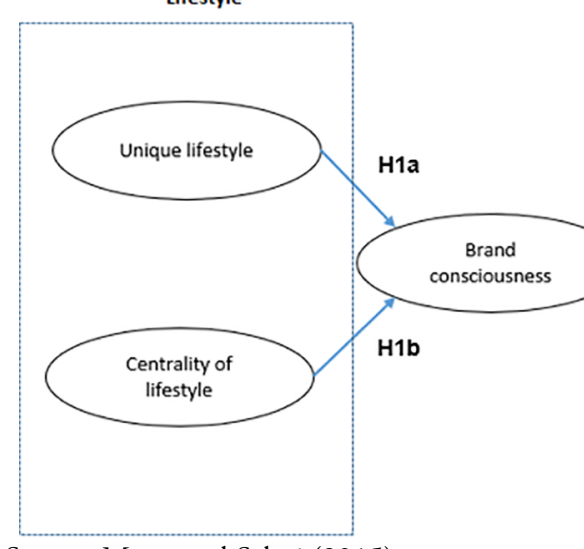

Source: Mann and Sahni (2015)
BBR

16,4

The following section explains the research hypotheses.

\subsection{THE CONSTRUCTION OF RESEARCH HYPOTHESES}

We included this section in the paper in order to explain the research hypotheses that were presented in the conceptual model of the research (Figure 1) as a result of the previous theoretical discussion. There are 10 (ten) hypotheses that served as the basis for the elaboration of the research instrument and later for the analysis of the results.

As previously emphasized, lifestyle is an indicator of consumption, revealing individual preferences for the purchase and use of products (Mann \& Sahni, 2015). According to the model, two dimensions of lifestyle - individual lifestyle and centrality of lifestyle - influence consumer brand consciousness. Thus, the following research hypothesis can be proposed.

H1a: Individual lifestyle significantly influences brand consciousness when purchasing products.

Regarding the centrality of lifestyle, Liao and Wang (2009) found a positive relationship between this dimension of lifestyle and brand consciousness. Thus, it seems to make sense to propose the following research hypothesis:

H1b: The centrality of lifestyle significantly influences brand consciousness in buying products.

Taking into account the discussion presented earlier, consumers who are brand conscious have the propensity to buy more expensive products to project an image of wealth and status, which would characterize a form of ostentation and signage. In this way, we are able to state the following research hypothesis:

H2a: Brand consciousness significantly influences consumer ostentation and signage.

In the same sense of the previous hypothesis, it can be said that the symbolic value of a product will increase considerably when consumers buy and use a product that is perceived as singular. This seems to be valid when the consumer realizes that the value of a product is inversely associated with the number of individuals who own it. The mark may, in this case, function as a form of singularizing. It is worth mentioning the work of Dubois and Duquesne (1993) that points to the existence of a strong relationship between brand consciousness and uniqueness. In this sense, the following hypothesis can be stated: 
Mann and Sahni (2015) emphasize that brand consciousness involves concern about how others perceive us and how the purchase and use of branded products enable these consumers to keep up with their social group. In this way, we are able to establish the hypothesis that:

H2c: Brand consciousness significantly influences consumer conformity.

Conspicuous consumption is evidenced when consumers intentionally advertise the consumption of products in order to reveal their self-image to others. Thus, ostentation and signaling has a significant impact on consumer status, since it is possible to recognize that symbolism, wealth, and achievement are success factors that indicate an improvement in status. Thus, we can hypothesize that:

H3a: Ostentation and signaling significantly influence status consumption.

Consumers acquire brands that are associated with wealth and status, providing selfimage distinct from themselves. O'Cass and Frost (2002) argue that acquiring status products is an indicator of social success, meaning uniqueness and subsequently influencing status consumption. In this sense, it is possible to propose the following hypothesis:

H3b: Uniqueness significantly influences the consumption of status.

Consumers are encouraged to buy and use products that are endorsed by their reference groups. As discussed earlier in the literature review section, social conformity implies action that is in line with group expectations or overcoming them, including brands that carry symbolism valued in the group (Mann \& Sahni, 2015). In this context, it is valid the proposition of the hypothesis that:

H3c: Social conformity significantly influences status consumption.

It is possible to find studies (Escalas \& Bettman, 2005; Grohmann, 2009) that emphasize the idea that consumers build their identity and express it through associations with brands. Bringing this finding to the scope of work, one can arrive at the following hypothesis:

H4: Brand consciousness significantly influences self-expression.

The concepts of conspicuous consumption and status consumption tend to consider that consumers buy, use and eventually make public their consumption to demonstrate their social position. The work by O'Cass and Frost (2002) tries to show this relationship, taking into account that the public use of certain products ends up complementing their selfexpression. Thus, we can propose the following hypothesis:

H5: Consumption of status significantly influences consumer self-expression.

After presenting the literature review, and explaining the hypotheses and the conceptual model, the article turns its attention to the discussion of the methodological procedures adopted in the empirical research. 


\section{METHOD}

Aiming to reach the objective proposed in the work, we conducted a survey through electronic collection. We implemented and made available in social networks, an electronic form elaborated in GoogleDocs, with the participation encouraged by e-mail to the personal contacts of the researchers. To participate in the survey, a questionnaire was added at the top of the form, which confirmed whether the respondent had attended a marriage ceremony in the last 6 (six) months. In the end, the survey had a total of 398 respondents.

The data collection instrument, in addition to the five profile questions, included scales referring to the five constructs (Lifestyle, Brand Consciousness, Conspicuous Consumption, Status Consumption and Self Expression) and their dimensions. At all scales, respondents were asked to state their degree of agreement/disagreement with the statements using an 11-point Likert scale, ranging from 0 (Strongly Disagree) to 10 (Strongly Agree). The scales can be viewed at the end of the text.

The scales underwent a process of adaptation and validation through the parallel translation technique (Malhotra, 1996). For this author, this technique consists of a method in which a committee of translators, each of whom is fluent in at least two languages, discusses alternative versions of a questionnaire and makes modifications until a consensus is reached. Three professionals (two marketing professors and one professional with fluency in the English language) were used in this process. Considering that there is the possibility of adjusting the questionnaire until a consensus is reached on the best form of translation. We considered this technique more suitable for the possibility of elaborating a consensus version from the view point of the committee members.

We applied the pre-test of the collection to a sample of 10 individuals to test the understanding of the questions. We asked respondents to present both questions and doubts about the research instrument. The doubts were duly discussed by the team and some adjustments were made in the questions.

In the data analysis phase, we initially verified the existence of two types of outliers: univariate and multivariate. The occurrences found were not taken from the sample because they believed that they were valid cases of the population and that, if they were eliminated, they could limit the generality of the multivariate analysis, although possibly improving their results (Hair, Black, Babin, Anderson, \& Tatham, 2009).

We performed the Structural Equation Modeling using the PLS approach. The PLS (Partial Least Square) approach offers an alternative to the traditional Covariance-based Structural Equation Modeling Techniques (CB-SEM) approach. The PLS method has been referred to as a soft modeling technique with minimal demand considering the measurement scales, sample size and residual distributions (Monecke \& Leisch, 2012). In addition, as some variables were considered non-normal by the analysis of asymmetry and kurtosis, we considered adequate the use of PLS.

Regarding the analysis of outliers, the univariate were diagnosed by standardizing the results, so that the mean of the variable was 0 and the standard deviation 1 . For this purpose, observations with standardized scores outside the range of | 3.29 | were considered outliers (Hair et al., 2009). In using this criterion, we found 51 univariate atypical observations. The multivariate outliers were diagnosed based on the Mahalanobis $\mathrm{D}^{2}$ measure. According to Hair et al. (2009), this measure verifies the position of each observation compared to the center of all observations in a set of variables, and, at the end, a chi-square test is performed. We considered as multivariate outliers, individuals with a significance level of less than 0.001 . Based on this method, we found 15 atypical observations in multivariate form. It is believed that the observations are valid cases of the population and, if they were eliminated, could limit the generality of the multivariate analysis, although possibly improving their results (Hair et al., 2009), we decided not to exclude any of the cases.
BBR

16,4 
BBR

16,4

It is worth mentioning that we used $\mathrm{R}^{2}$ and GoF to verify the quality of the goodness of fit (Tenenhaus, Vinzi, Chatelin, \& Lauro, 2005). $\mathrm{R}^{2}$ represents on a scale of $0 \%$ to $100 \%$ how much the independent constructs explain the dependents ones, and the closer to $100 \%$ the better. The GoF is a geometric mean of the average MEV of the constructs and the mean of the $\mathrm{R}^{2}$ of the model and varies from $0 \%$ to $100 \%$. There is still no cut-off value in the literature to consider a fitting as good or bad, but it is known that the higher the value the better the goodness of fit. It should be noted that the GoF index of $59.29 \%$ is considered an indication of good performance of the model as a whole, since it exceeds the $36 \%$ cut-off established by Wetzels, Odekerken-Schröder and van Oppen (2009), a result that points to its high explanatory capacity.

The Mann-Whitney, Kruskal-Wallis tests and the Spearman Correlations were used to compare the indices created by the model in relation to the characterizing variables. It is worth mentioning that the value of statistical power was calculated and that all the endogenous variables of the model surpassed the value of $80 \%$, considering both the $5 \%$ and $1 \%$ significance levels. The software we used in the analyzes was $\mathrm{R}$ (version 3.1.3).

\section{RESULTS}

\subsection{Characterization OF Respondents}

It can be stated that the majority of respondents are female $(63.57 \%)$ and declared between 18 and 29 years old (52.51\%) and between 30 and 39 years old $(31.41 \%)$. The most frequent marital status is single $(58.48 \%)$, followed by the married stratum $(34.43 \%)$. It should also be mentioned that all the respondents stated that they had higher or completed schooling.

\subsection{DESCRIPTIVE ANALYSIS OF THE CONSTRUCTS}

The analysis of Table 1 shows that all constructs, except for Lifestyle, presented low average values, indicating that the respondents disagree with the statements presented.

Table 1 - Descriptive analysis of the items of the constructs

\begin{tabular}{|c|c|c|c|c|}
\hline Constructs & Items & Mean & S.D. & B.I. $-95 \%^{1}$ \\
\hline \multirow[t]{3}{*}{ Unique lifestyle } & EVI1 & 7.53 & 2.21 & {$[7.30 ; 7.76]$} \\
\hline & EVI2 & 7.64 & 2.59 & {$[7.39 ; 7.90]$} \\
\hline & EVI3 & 5.99 & 2.65 & {$[5.75 ; 6.24]$} \\
\hline \multirow[t]{3}{*}{ Centrality to lifestyle } & CEV1 & 3.02 & 2.76 & {$[2.75 ; 3.30]$} \\
\hline & CEV2 & 2.86 & 2.74 & {$[2.59 ; 3.11]$} \\
\hline & CEV3 & 0.79 & 1.66 & {$[0.63 ; 0.96]$} \\
\hline \multirow[t]{3}{*}{ Brand Consciousness } & CMA1 & 1.47 & 2.06 & {$[1.27 ; 1.68]$} \\
\hline & CMA2 & 3.24 & 2.87 & {$[2.95 ; 3.51]$} \\
\hline & CMA3 & 4.01 & 2.88 & {$[3.72 ; 4.29]$} \\
\hline \multirow{3}{*}{$\begin{array}{l}\text { Ostentation } \\
\text { signaling }\end{array}$} & OSI1 & 2.70 & 2.74 & {$[2.45 ; 2.97]$} \\
\hline & OSI2 & 2.19 & 2.77 & {$[1.92 ; 2.49]$} \\
\hline & OSI3 & 2.06 & 2.54 & {$[1.82 ; 2.31]$} \\
\hline \multirow[t]{3}{*}{ Uniqueness } & SIN1 & 2.65 & 2.93 & {$[2.37 ; 2.95]$} \\
\hline & SIN2 & 2.44 & 2.88 & {$[2.16 ; 2.76]$} \\
\hline & SIN3 & 3.07 & 2.93 & {$[2.77 ; 3.37]$} \\
\hline \multirow[t]{3}{*}{ Social conformity } & CSO1 & 1.84 & 2.49 & {$[1.60 ; 2.10]$} \\
\hline & $\mathrm{CSO} 2$ & 1.79 & 2.59 & {$[1.54 ; 2.03]$} \\
\hline & $\mathrm{CSO} 3$ & 1.46 & 2.27 & {$[1.23 ; 1.69]$} \\
\hline
\end{tabular}




\begin{tabular}{lllll}
\hline & & & & \\
\hline Status Consumption & CST1 & 2.05 & 2.65 & {$[1.80 ; 2.33]$} \\
& CST2 & 2.24 & 2.92 & {$[1.94 ; 2.53]$} \\
& CST3 & 1.98 & 2.59 & {$[1.73 ; 2.24]$} \\
& CST4 & 1.42 & 2.33 & {$[1.19 ; 1.64]$} \\
\hline Self-expression & AEX1 & 1.38 & 2.22 & {$[1.16 ; 1.61]$} \\
& AEX2 & 1.50 & 2.37 & {$[1.28 ; 1.74]$} \\
\hline
\end{tabular}

Source: Research data (2015)

Note: ${ }^{1}$ Bootstrap interval.

\subsection{Modeling of Structural Equations}

Initially, it is worth mentioning that in the analysis of the measurement model the convergent validity, the discriminant validity and the reliability of the constructs are verified. To test the convergent validity of the constructs, we used the criterion proposed by Fornell and Larcker (1981). The criterion of the convergent evaluation evaluates the degree to which two measures of the same concept are correlated, whereas the discriminant evaluation measures the degree to which one construct is truly different from the others (Hair et al., 2009). In order to verify the convergent validity, the criterion proposed by Fornell and Larcker (1981), which defines the convergent validity range when the Mean Extracted Variance (MEV) is greater than 50\% (Henseler, Ringle, \& Sinkovics, 2009) or $40 \%$ in the case of exploratory research (Nunnally \& Bernstein, 1994).

The discriminant validity was verified through the analysis of the crossed factor loadings, as suggested by Barclay, Higgins and Thompson (1995). To measure the reliability of the constructs, we used Cronbach's Alpha (CA) and Compound Reliability (CR). According to Tenenhaus et al. (2005), the CA and CR indices should be greater than 0.70 for an indication of construct reliability. We used the Bootstrap method to calculate the confidence intervals for the weights of the measurement model, providing information on the variability of the estimated parameters, thus providing an important validation of the results. Variables with non-significant weights should be excluded because they do not contribute in a relevant way to the latent variable.

For a good measurement model, we expect factor loadings above 0.70 and commonality above 0.40 , but items with factor loadings lower than 0.50 should be eliminated (Hair et al., 2009), because they contribute significantly to the formation of the latent variable, they undermine the scope of the basic assumptions for the validity and quality of the indicators created to represent the concept of interest. Table 2 shows the weights, factor loadings and commonalities of the initial and final measurement model. It is observed that the item EVI1 "I like to try new ways of doing things" presented insignificant weight and, for that reason, was excluded from the model. After the exclusion of this item, we adjusted the final measurement model. In this way, it can be emphasized, based on the final measurement model, that all items presented factor loadings greater than 0.50 . In addition, it can be affirmed that in evaluating the Bootstrap confidence intervals, we can observe that all weights were significant, confirming the importance of all the items for the formation of the indicator that represents the construct.

Table 3 presents the analysis of convergent validation, discriminant validation, dimensionality and reliability of the constructs of the measurement model.

From Table 3, four considerations can be made. Firstly, the Individual Lifestyle, Centrality of Lifestyle, and Brand Consciousness constructs did not show CA reliability indexes above 0.70 , but all other constructs had CR reliability indexes above 0.70 , indicating their 
BBR

16,4

360

Table 2 - Initial and final measurement model

\begin{tabular}{|c|c|c|c|c|c|c|c|c|c|}
\hline \multirow{2}{*}{ Constructs } & \multirow{2}{*}{ Items } & \multicolumn{4}{|c|}{ Initial Model } & \multicolumn{4}{|c|}{ Final Model } \\
\hline & & Weight & B. I.- $95 \%{ }^{1}$ & F.L. $^{2}$ & Com. ${ }^{3}$ & Weight & I.C. $-95 \%^{1}$ & C.F. ${ }^{2}$ & Com. ${ }^{3}$ \\
\hline \multirow[t]{3}{*}{ Unique lifestyle } & EVI1 & 0.19 & {$[-0.16 ; 0.38]$} & 0.61 & 0.37 & - & - & - & - \\
\hline & EVI2 & 0.52 & {$[0.35 ; 0.73]$} & 0.77 & 0.60 & 0.58 & {$[0.42 ; 0.76]$} & 0.81 & 0.65 \\
\hline & EVI3 & 0.57 & {$[0.43 ; 0.72]$} & 0.85 & 0.72 & 0.63 & {$[0.44 ; 0.78]$} & 0.84 & 0.71 \\
\hline \multirow[t]{3}{*}{ Centrality to lifestyle } & CEV1 & 0.61 & {$[0.54 ; 0.70]$} & 0.85 & 0.72 & 0.61 & {$[0.54 ; 0.70]$} & 0.85 & 0.72 \\
\hline & CEV2 & 0.34 & {$[0.27 ; 0.41]$} & 0.66 & 0.44 & 0.34 & {$[0.27 ; 0.40]$} & 0.66 & 0.44 \\
\hline & CEV3 & 0.38 & {$[0.31 ; 0.45]$} & 0.67 & 0.45 & 0.38 & {$[0.31 ; 0.45]$} & 0.67 & 0.45 \\
\hline \multirow[t]{3}{*}{ Brand Consciousness } & CMA1 & 0.47 & {$[0.41 ; 0.53]$} & 0.75 & 0.56 & 0.47 & {$[0.41 ; 0.53]$} & 0.74 & 0.55 \\
\hline & CMA2 & 0.41 & {$[0.37 ; 0.45]$} & 0.81 & 0.66 & 0.41 & {$[0.37 ; 0.45]$} & 0.82 & 0.66 \\
\hline & CMA3 & 0.40 & {$[0.36 ; 0.44]$} & 0.80 & 0.64 & 0.40 & {$[0.36 ; 0.44]$} & 0.80 & 0.64 \\
\hline \multirow{3}{*}{$\begin{array}{l}\text { Ostentation } \\
\text { signaling }\end{array}$} & OSI1 & 0.37 & {$[0.34 ; 0.40]$} & 0.84 & 0.71 & 0.37 & {$[0.34 ; 0.39]$} & 0.84 & 0.71 \\
\hline & OSI2 & 0.39 & {$[0.36 ; 0.41]$} & 0.86 & 0.74 & 0.39 & {$[0.36 ; 0.41]$} & 0.86 & 0.74 \\
\hline & OSI3 & 0.41 & {$[0.38 ; 0.44]$} & 0.88 & 0.78 & 0.41 & {$[0.38 ; 0.44]$} & 0.88 & 0.78 \\
\hline \multirow[t]{3}{*}{ Uniqueness } & SIN1 & 0.49 & {$[0.43 ; 0.54]$} & 0.86 & 0.73 & 0.49 & {$[0.44 ; 0.54]$} & 0.86 & 0.73 \\
\hline & SIN2 & 0.47 & {$[0.42 ; 0.52]$} & 0.86 & 0.74 & 0.47 & {$[0.42 ; 0.52]$} & 0.86 & 0.74 \\
\hline & SIN3 & 0.29 & {$[0.22 ; 0.34]$} & 0.63 & 0.40 & 0.29 & {$[0.23 ; 0.35]$} & 0.63 & 0.40 \\
\hline \multirow[t]{3}{*}{ Social conformity } & CSO1 & 0.36 & {$[0.34 ; 0.38]$} & 0.89 & 0.79 & 0.36 & {$[0.34 ; 0.38]$} & 0.89 & 0.79 \\
\hline & $\mathrm{CSO} 2$ & 0.38 & {$[0.36 ; 0.40]$} & 0.93 & 0.86 & 0.38 & {$[0.36 ; 0.40]$} & 0.93 & 0.86 \\
\hline & $\mathrm{CSO} 3$ & 0.36 & {$[0.35 ; 0.38]$} & 0.92 & 0.84 & 0.36 & {$[0.35 ; 0.38]$} & 0.92 & 0.84 \\
\hline \multirow[t]{4}{*}{ Status Consumption } & CST1 & 0.31 & {$[0.29 ; 0.34]$} & 0.89 & 0.79 & 0.31 & {$[0.30 ; 0.34]$} & 0.89 & 0.79 \\
\hline & CST2 & 0.25 & {$[0.22 ; 0.26]$} & 0.81 & 0.65 & 0.25 & {$[0.23 ; 0.26]$} & 0.81 & 0.65 \\
\hline & CST3 & 0.30 & {$[0.28 ; 0.32]$} & 0.87 & 0.76 & 0.30 & {$[0.28 ; 0.32]$} & 0.87 & 0.76 \\
\hline & CST4 & 0.29 & {$[0.27 ; 0.31]$} & 0.89 & 0.79 & 0.29 & {$[0.27 ; 0.31]$} & 0.89 & 0.79 \\
\hline \multirow[t]{3}{*}{ Self-expression } & AEX1 & 0.37 & {$[0.35 ; 0.38]$} & 0.91 & 0.83 & 0.37 & {$[0.35 ; 0.39]$} & 0.91 & 0.83 \\
\hline & AEX2 & 0.36 & {$[0.35 ; 0.39]$} & 0.91 & 0.83 & 0.36 & {$[0.34 ; 0.39]$} & 0.91 & 0.83 \\
\hline & AEX3 & 0.36 & {$[0.35 ; 0.38]$} & 0.93 & 0.87 & 0.36 & {$[0.35 ; 0.38]$} & 0.93 & 0.87 \\
\hline
\end{tabular}

Source: Research data (2015)

Note: ${ }^{1}$ Bootstrap interval; ${ }^{2}$ Factor loading; ${ }^{3}$ Commonality.

Table 3 - Validation of the Measurement Model

\begin{tabular}{lcccccc}
\hline Constructs & Items & C.A. ${ }^{1}$ & C.R. & Dim. $^{2}$ & AVE $^{4}$ & MSV $^{5}$ \\
\hline Unique lifestyle & 2 & 0.53 & 0.81 & 1 & 0.68 & 0.06 \\
Centrality to lifestyle & 3 & 0.58 & 0.78 & 1 & 0.54 & 0.52 \\
Brand Consciousness & 3 & 0.69 & 0.83 & 1 & 0.62 & 0.43 \\
Ostentation and signaling & 3 & 0.83 & 0.90 & 1 & 0.74 & 0.60 \\
Uniqueness & 3 & 0.70 & 0.83 & 1 & 0.62 & 0.51 \\
Social conformity & 3 & 0.90 & 0.94 & 1 & 0.83 & 0.83 \\
Status Consumption & 4 & 0.89 & 0.92 & 1 & 0.75 & 0.83 \\
Self-expression & 3 & 0.91 & 0.94 & 1 & 0.84 & 0.76
\end{tabular}

Source: Research data (2015)

Note: ${ }^{1}$ Cronbach's Alpha; ${ }^{2}$ Composite Reliability; ${ }^{3}$ Dimensionality; ${ }^{4}$ Average Variance Extracted; ${ }^{5}$ Maximum Shared Variance

reliability. Second, we can say that all the constructs were one-dimensional. Thirdly, all the constructs had a CVE greater than 0.50 , evidencing the convergent validation. Finally, it should be pointed out that, according to the criterion proposed by Fornell and Larcker (1981), there was no discriminant validation for the constructs analyzed, since there were shared variances greater than the respective MEVs. However, using the cross-factor loading 
method (Barclay et al., 1995) the discriminant validation criterion was reached, since the factorial loads of the items were higher than all the respective cross-factor loadings, as can be observed in Table 4.

Table 4 - Discriminant validation by cross-factor loading method.

\begin{tabular}{|c|c|c|c|}
\hline Constructs & Items & C.F. ${ }^{1}$ & $\operatorname{Max}($ C.F.C.) \\
\hline \multirow{2}{*}{ Unique lifestyle } & EVI2 & 0.81 & 0.23 \\
\hline & EVI3 & 0.84 & 0.21 \\
\hline \multirow{3}{*}{ Centrality to lifestyle } & CEV1 & 0.85 & 0.65 \\
\hline & CEV2 & 0.66 & 0.43 \\
\hline & CEV3 & 0.67 & 0.62 \\
\hline \multirow{3}{*}{ Brand Consciousness } & CMA1 & 0.74 & 0.61 \\
\hline & CMA2 & 0.82 & 0.49 \\
\hline & CMA3 & 0.80 & 0.50 \\
\hline \multirow{3}{*}{ Ostentation and signaling } & OSI1 & 0.84 & 0.65 \\
\hline & OSI2 & 0.86 & 0.67 \\
\hline & OSI3 & 0.88 & 0.71 \\
\hline \multirow{3}{*}{ Uniqueness } & SIN1 & 0.86 & 0.69 \\
\hline & SIN2 & 0.86 & 0.62 \\
\hline & SIN3 & 0.63 & 0.34 \\
\hline \multirow{3}{*}{ Social conformity } & $\mathrm{CSO} 1$ & 0.89 & 0.78 \\
\hline & $\mathrm{CSO} 2$ & 0.93 & 0.86 \\
\hline & $\mathrm{CSO} 3$ & 0.92 & 0.88 \\
\hline \multirow{4}{*}{ Status Consumption } & CST1 & 0.89 & 0.86 \\
\hline & CST2 & 0.81 & 0.71 \\
\hline & CST3 & 0.87 & 0.78 \\
\hline & CST4 & 0.89 & 0.80 \\
\hline \multirow{3}{*}{ Self-expression } & AEX1 & 0.91 & 0.85 \\
\hline & AEX2 & 0.91 & 0.76 \\
\hline & AEX3 & 0.93 & 0.80 \\
\hline
\end{tabular}

Source: Research data (2015)

Note: ${ }^{1}$ Factor Load

\subsection{Structural Model}

As previously described in the method section, the measurement model and regression model were performed using the PLS (Partial Least Square) method. Structural Equation Models (SEM) are very popular in many disciplines, and the PLS (Partial Least Square) approach is an alternative to the traditional approach based on covariance.

Table 5 and Figure 2 present the results of the structural model.

After the description step, the next section will discuss the search results.

\section{DISCUSSION}

From what was presented in the structural model, it is important to highlight the following points. In the first place, the model presented a GoF of $59.29 \%$, which can be considered a good result taking into account the context and the particularities of the constructs involved in the research. In addition, it can be emphasized that the Bootstrap confidence intervals are in agreement with the p-values, evidencing more validity of the results.

Regarding the brand consciousness construct, the results indicated that there was significant ( $p$-value $=0.035)$ and positive influence $(\beta=0.08[0.01 ; 0.17])$ of Individual Lifestyle on Brand Consciousness. Thus, the greater the individual Lifestyle, the greater 


\begin{tabular}{lcccccc}
\hline Endogenous & Exogenous & $\beta$ & I.C. $-95 \%{ }^{1}$ & E.P. $(\beta)^{2}$ & p-value & $\mathrm{R}^{2}$ \\
\hline \multirow{2}{*}{ Brand Consciousness } & Unique lifestyle & 0.08 & {$[0.01 ; 0.17]$} & 0.04 & 0.035 & $41.40 \%$ \\
& Centrality to lifestyle & 0.62 & {$[0.55 ; 0.68]$} & 0.04 & 0.000 & \\
Ostentation and signaling & Brand Consciousness & 0.65 & {$[0.58 ; 0.72]$} & 0.04 & 0.000 & $42.80 \%$ \\
Uniqueness & Brand Consciousness & 0.49 & {$[0.40 ; 0.58]$} & 0.04 & 0.000 & $24.20 \%$ \\
Social conformity & Brand Consciousness & 0.59 & {$[0.50 ; 0.66]$} & 0.04 & 0.000 & $34.30 \%$ \\
& Ostentation and signaling & 0.10 & {$[0.00 ; 0.22]$} & 0.04 & 0.004 & \\
Status Consumption & $\quad$ Uniqueness & 0.10 & {$[0.03 ; 0.18]$} & 0.03 & 0.000 & $84.80 \%$ \\
& Social conformity & 0.77 & {$[0.67 ; 0.87]$} & 0.03 & 0.000 & \\
\multirow{3}{*}{ Self-expression } & Brand Consciousness & 0.04 & {$[-0.02 ; 0.12]$} & 0.03 & 0.191 & $71.40 \%$ \\
& Status Consumption & 0.82 & {$[0.74 ; 0.88]$} & 0.03 & 0.000 & \\
\hline
\end{tabular}

Source: Research data (2015)

Note: ${ }^{1}$ Bootstrap Interval; ${ }^{2} \mathrm{GoF}=59.29 \%$.

Figure 2 - Structural model

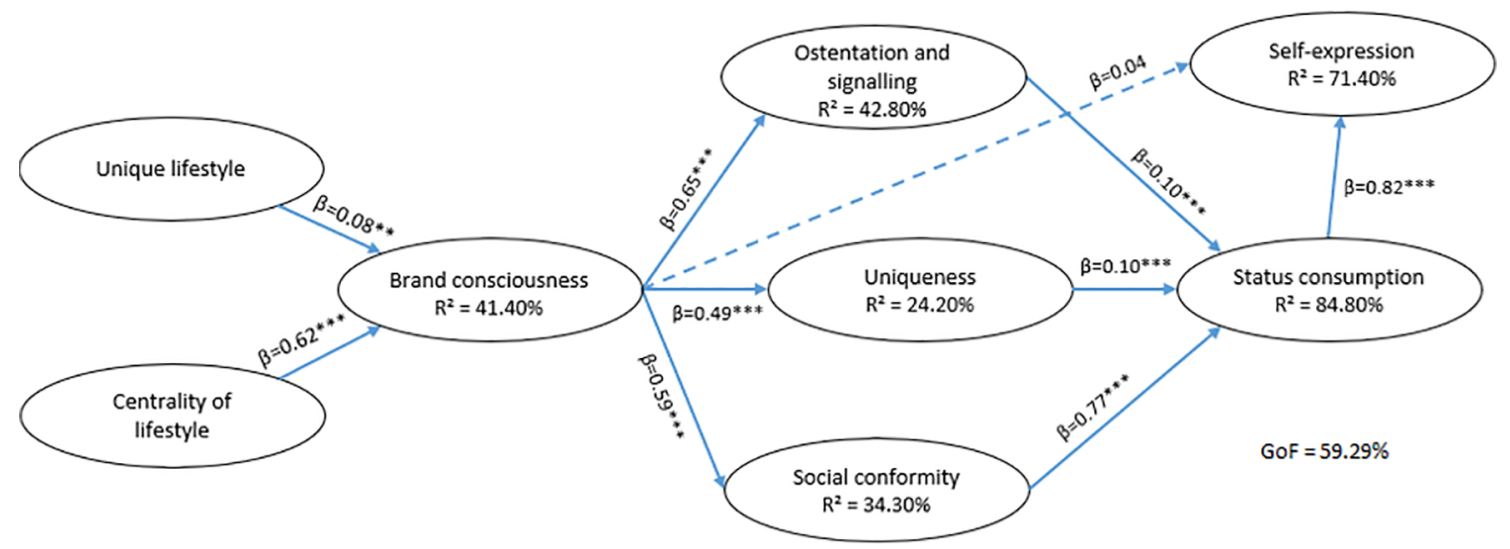

Source: Research data (2015)

the brand consciousness. In addition, there was significant ( $\mathrm{p}$-value $=0.000$ ) and positive influence $(\beta=0.62[0.55 ; 0.68])$ of Centrality of lifestyle on brand consciousness. Therefore, the greater the Centrality of lifestyle, the greater the brand consciousness. In this way, the individual Lifestyle and the Centrality of the lifestyle were able to explain $41.40 \%$ of brand consciousness. These findings point to interesting theoretical findings, since consumers are brand conscious because brands are central to both their individual lifestyles and the centrality of their lifestyles.

With respect to the Ostentation and Signage it can be affirmed that it was possible to measure a significant $(p$-value $=0.000)$ and positive influence $(\beta=0.65[0.58 ; 0.72])$ of Brand Consciousness on the Ostentation and Signage. In this way, the greater the brand consciousness, the greater the ostentation and signage.

Regarding the Uniqueness, the results showed significant ( $p$-value $=0.000)$ and positive influence $(\beta=0.49[0.40,0.58])$ of Brand Consciousness on Uniqueness. Therefore, we can conclude that the greater the brand consciousness, the greater the Uniqueness.

In relation to the social Conformity construct, the model indicated that there was significant $(p$-value $=0.000)$ and positive influence $(\beta=0.59[0.50 ; 0,66])$ of Brand Consciousness on Social Conformity. In this way, the greater the brand consciousness, the greater the Social Conformity will be. 
For the Self-expression construct, two points were noticed. Initially, we observed the absence of significant influence $(p$-value $=0.191, \beta=0.04[-0.02,0.12])$ of Brand Consciousness on Self-Expression. The second one points out that, unlike the first one, there was a significant $(p$-value $=0.000)$ and positive influence $(\beta=0.82[0.74,0.88])$ of the Status Consumption on Self Expression, which leads to the conclusion that the higher the Status Consumption, the greater the Self-expression.

Finally, and of paramount importance to the objectives of the work, in relation to the Status Consumption, we came up with some interesting findings. First, we can verify the significant $(p$-value $=0.004)$ and positive influence $(\beta=0.10[0.00 ; 0.22])$ of Significance and Signage on Status Consumption. Therefore, the greater the Ostentation and Signage, the greater the Status Consumption. Second, the results showed significant (p-value = $0.000)$ and positive influence $(\beta=0.10[0.03 ; 0.18])$ of Uniqueness on Status Consumption. Therefore, the greater the Uniqueness, the greater the Status Consumption. Another relevant result is related to the indication of significant $(p$-value $=0.000)$ and positive influence $(\beta$ $=0.77[0.67,0.87])$ of Social Conformity over Status Consumption. Thus, the greater the Social Conformity, the greater the Status Consumption. Finally, it should be emphasized that the Ostentation and Signage, Uniqueness and Social Conformity constructs were able to explain $84.80 \%$ of Status Consumption.

Returning to the proposed model and taking into account that conspicuous consumption has three subdimensions, that is, Ostentation and Signage, Uniqueness and Social Conformity, the results presented allow us reaching some findings that seem to be relevant to the literature. We noted that conspicuous consumption is directly related to status consumption. In other words, the results highlight that consumers' decision to show their status and wealth, as well as the desire for social acceptance, triggers the purchase of status products. The results indicate that consumers' desire to relate to their social groups and to communicate their wealth and belonging to a certain class ultimately encourages them to buy branded products as a way to gain status, respect and conformity in their social groups.

Another interesting result has to do with the observation that consumption by status has a greater influence on self-expression than brand consciousness. It is perceived, therefore, that the intention of the consumer to buy and display branded products is to convey information about themselves to others; however, it is the consumption of status through products associated with wealth and perception of status that enables this greater self-expression capacity.

As far as the wedding ceremony is concerned, the results also seem to reveal some interesting points for discussion. First, from the perspective of consumer behavior, the results help to better understand the motives that lead consumers to conspicuous consumption on marriage occasions. This is certainly, due to the fact that the celebration of marriage can be considered as an opportunity for the individual to "show off" to friends, family and other acquaintances, in order to demonstrate and/or announce their social position through the use of products considered as differentiated by brands.

From these results, it is possible to rescue the hypotheses proposed for the research. According to Table 6, we can see that of the ten hypotheses established, only one of them (H4) was not supported by empirical research. This result is not consistent with the studies by Escalas and Bettman (2005) and Grohmann (2009), which sustain the idea that consumers construct their identity through the use of brands. However, the non-confirmation of the hypothesis ends up reinforcing the central proposal of the article when it reveals that the consumption of status influences more directly the self-expression than the brand 
BBR

16,4

consciousness, that is, it makes sense to think that the intention of the consumer to buy and display the branded products is to transmit information about themselves to others.

Thus, the study seems to offer evidence that there is an interrelationship between conspicuous consumption and status consumption.

Faced with these discussions, we can start with the conclusions section of the paper, in which diverse issues such as work limitations, managerial and theoretical implications of work, as well as suggestions for future studies can be exposed.

Table 6 - Hypothesis Test

\begin{tabular}{llc}
\hline Hypothesis & & Result \\
\hline H1a & Individual lifestyle significantly influences brand consciousness when purchasing products & Supported \\
H1b & The centrality of lifestyle significantly influences brand consciousness in buying products & Supported \\
H2a & Brand consciousness significantly influences Consumer ostentation and signage & Supported \\
H2b & Brand consciousness significantly influences the uniqueness of the consumer & Supported \\
H2c & Brand consciousness significantly influences consumer conformity & Supported \\
H3a & Ostentation and signaling significantly influence status consumption & Supported \\
H3b & Uniqueness significantly influences status consumption & Supported \\
H3c & Social conformity significantly influences status consumption & Supported \\
H4 & Brand consciousness significantly influences self-expression & Not Supported \\
H5 & Status consumption significantly influences consumer self-expression & Supported \\
\hline
\end{tabular}

Source: Data collection (2015)

\section{CONCLUSIONS}

Rescuing the proposed objective of the research, we can affirm that it was achieved, since it was intended to discuss the relationship between the concepts of Conspicuous Consumption, Status Consumption and Self-expression, as well as to verify in what way the constructs Brand Consciousness and Lifestyle may be associated with Conspicuous Consumption and Self-expression. At this point, it should be noted that such initiative has a pioneering character in Brazil, since there is a gap in the consumer behavior literature in the understanding of these relations. The results of the study bring interesting contributions by confirming that there is in fact a relatively strong association between the constructs Status Consumption and Self Expression, as well as it being possible to verify a significant and positive influence between Conspicuous Consumption and Status Consumption. In other words, the results seem to provide evidence that Conspicuous Consumption has a consequence relation with Brand Consciousness. At the same time, Conspicuous Consumption acts as antecedent of Status Consumption, which, in turn, has a strong relation with Self-expression.

It can be said that the discussion advances in relation to the original model by Mann and Sahni (2015) by contributing with the consumption researchers to the discussion of conspicuous consumption relations and their antecedents and consequents in a different cultural context. In addition, the study still brings to the debate theoretical discussions useful to the field that were not contemplated in the original paper from the empirical test conducted. 
When comparing the results of the original work conducted by Mann and Sahni (2015), we can reach some interesting conclusions. We found that many of the results coincide. The centrality of lifestyle influences brand consciousness. In turn, brand consciousness has an influence on the three dimensions of conspicuous consumption. Status consumption has a strong influence on self-expression, which does not happen in the relationship between brand consciousness and self-expression. The exception, however, is that in the original study no influence was detected between individual lifestyle and brand consciousness. In the study conducted in Brazil, this influence was significant. Another difference has to do with the question of uniqueness that in the original study was shown to have no significant influence, whereas in the study in Brazil it was perceived as a weak influence. Social conformity more strongly influences status consumption than in the original study. This last difference deserves attention because it seems that in the Brazilian culture, it is important to consider the relational issues that lead to a greater search for social conformity.

It is not excessive to emphasize that the work, in proposing this discussion brings to light concepts that are expensive in the field of consumer behavior. Returning to the discussions in the introductory section, all of these concepts remain important to consumer researchers. The context of marriage ceremonies in Brazil was relevant to the study.

Regarding the practical implications, the results of the study throw light on some issues that are useful for marketing managers in communication, targeting and positioning strategies. Firstly, it reveals a tendency for consumers to relate branded products to conspicuous consumption and self-expression. In this way, the research indicates that marketing communication strategies could position products with these attributes. In addition, marketing managers could reinforce the concept of product-related uniqueness in a context of conspicuous consumption, while at the same time emphasizing the sense of conformity with the social group that the consumer seeks to create links. The study also presents useful results for managers of event companies (wedding ceremonies and other special occasions such as birthday parties and graduations) by relating the feeling of uniqueness, social conformity and, consequently, conspicuity and status to the experience in these events.

At this point, it is pertinent to discuss some limitations of the research. A first limitation of the work has to do with the question of sampling. As previously described, data collection took place electronically. Although this type of data collection in marketing research has grown in recent years and presents a number of advantages, it is not unreasonable to consider that it also presents some problems, among them, the "vice" of accessing individuals with poorly differentiated profiles. In the case of this research, this situation was evident, since more than $63 \%$ of the sample was female, more than $52 \%$ declared between the ages of 18 and 29 and more than 58\% said they were single. Another important issue that constitutes a limitation of the work refers to the so-called bias of social desirability (Crowne \& Marlowe, 1960). This concept can be understood as the result of responses attributed by the respondent who is not based on what he actually believes or practices, but on what he perceives to be socially appropriate to respond. We must also mention the cultural issue that was not taken into account in the design of the study.

Finally, it is interesting to identify some suggestions for the development of future research. The list of study possibilities involving the constructs contemplated in the article is especially extensive in view of the various relationships that can be researched, as well as 
BBR

16,4 the innumerable contexts in which the model can be tested. Among these contexts, special occasions such as birthdays, baptisms, weddings, graduations and other celebrations may be cited in which an expressive symbolic and experiential charge is predominant. Other investigations could move towards narrowing the concepts of conspicuous consumption and status consumption toward luxury goods. It would also be interesting to conduct comparative studies involving relationships between concepts, taking into account different groups of consumers segmented by income, age, gender, among other variables in order to confront the results. It would not be inappropriate to propose investigations in which the objective was to evaluate new relations involving the constrictions of consumption of status and conspicuous consumption. On the other hand, since all the concepts dealt with in the work refer to a series of questions involving cultural issues which, in terms of regional differences, would also be revealing to try to confront results of research conducted in different locations.

\section{REFERENCES}

Abrafesta. Associação Brasileira de Eventos. (2018). Recuperado em 06 agosto, 2018, de https://abrafesta. com.br/34-quem-somos

Amaldoss, W., \& Jain, S. (2005). Pricing of conspicuous goods: A competitive analysis of social effects. Journal of Marketing Research, 42(1), 30-42.

Bagwell, L. S., \& Bernheim, B. D. (1996). Veblen effects in a theory of conspicuous consumption. The American Economic Review, 86(3), 349-373.

Barclay, D., Higgins, C., \& Thompson, R. (1995). The partial least squares (PLS) approach to causal modeling: Personal computer adoption and use as an illustration. Technology Studies, 2(2), 285-309.

Belk, R. W. (1978). Assessing the Effects of Visible Consumption on Impression Formation. Advances in Consumer Research, 5(1), 39-47.

Belk, R. W. (1988). Possessions and the extended self. Journal of Consumer Research, 15(2), 139-168.

Carvalho, D. L. T., \& Pereira, R. C. F. A. (2013). Conspicuidade no Consumo do Ritual do Casamento. Anais do Encontro da Associação Nacional de Pós-Graduação e Pesquisas em Administração [EnANPAD], Rio de Janeiro, RJ, Brasil, 37.

Corneo, G., \& Jeanne, O. (1997). Conspicuous consumption, snobbism and conformism. Journal of Public Economics, 66(1), 55-71.

Crowne, D. P., \& Marlowe, D. (1960). A new scale of social desirability independent of psychopathology. Journal of Consulting Psychology, 24(4), 349-354.

Dubois, B., \& Duquesne, P. (1993). The market of luxury goods: income versus culture. European Journal of Marketing, 27(1), 35-44.

Eastman, J. K., Goldsmith, R. E., \& Flynn, L. R. (1999). Status consumption in consumer behavior: Scale development and validation. Journal of Marketing Theory and Practice, 7(3), 41-52.

Escalas, J. E., \& Bettman, J. (2005). Self-construal, reference groups and brand meaning. Journal of Consumer Research, 32(3), 378-389.

Fornell, C., \& Larcker, D. F. (1981). Evaluating structural equation models with unobservable variables and measurement error. Journal of marketing research, 18(1), 39-50.

Grohmann, B. (2009). Gender dimensions of brand personality. Journal of Marketing, 46(1), 105-119.

Hair, J. F., Black, W. C., Babin, B. J., Anderson, R. E., \& Tatham, R. L. (2009). Análise Multivariada de Dados. Porto Alegre: Bookman.

Henseler, J., Ringle, C. M., \& Sinkovics, R. R. (2009). The use of partial least squares path modeling in international marketing. Advances in international marketing, 20(1), 277-319.

Leigh, J. H., \& Gabel, T. G. (1992). Symbolic interactionism: its effects on consumer behaviour and implications for marketing strategy. Journal of Services Marketing, 6(3), 5-16.

Liao, J., \& Wang, L. (2009). Face as mediator of the relationship between material value and brand consciousness. Psychology and Marketing, 26(11), 987-1001.

McCracken, G. (1987). The History of Consumption: A literature review and consumer guide. Journal of Consumer Policy, 10, 139-166.

Malhotra, N. K. (2001). Pesquisa de Marketing: uma orientação aplicada. Porto Alegre: Bookman. 
Mann, B. J. S., \& Sahni, S. K. (2015). Exploring the Drivers of Status Consumption for the Wedding Occasion. International Journal of Market Research, 57(2), 179-202.

Marcoux, J. S., Filiatrault, P., \& Cheron, E. (1997). The attitudes underlying preferences of young urban educated Polish consumers towards products made in western countries. Journal of International Consumer Marketing, 9(4), 5-29.

Mason, R. (1984). Conspicuous Consumption: a literature review. European Journal of Marketing, 18(3), 26-39.

Mason, R. (2002). Conspicuous consumption in economic theory and thought. In E. Fullbrook (Ed.), Intersubjectivity in Economics: Agents and Structures (pp. 85-104). London: Routledge.

Miller, C., Mcintyre, S., \& Mantrala, M. (1993). Toward formalizing fashion theory. Journal of Marketing Research, 30(2), 142-157.

Monecke, A., \& Leisch, F. (2012). semPLS: Structural Equation Modeling Using Partial Least Squares. Journal of Statistical Software, 48(3), 1-32.

Nunnaly, J., \& Bernstein, I. H. (1994). Psychometric Theory. New York: McGraw-Hill.

O'Cass, A., \& Frost, H. (2002). Status brands: examining the effects of non-product-related brand associations on status and conspicuous consumption. Journal of Product \& Brand Management, 11(2), 67-88.

O'Cass, A., \& McEwen, H. (2004). Exploring consumer status and conspicuous consumption. Journal of Consumer Behaviour, 4(1), 25-39.

Page, C. (1992). A history of conspicuous consumption. In F. W. Rudmin \& M. Richins (orgs.) Meaning, Measure, and Morality of Materialism. Provo, UT: Association for Consumer Research.

Simmel, G. (1957). Fashion. American Journal of Sociology, 62(6), 541-558.

Shukla, P. (2010). Status consumption in cross-national context: Socio-psychological, brand and situational antecedents. International Marketing Review, 27(1), 108-129.

Solomon, M. R. (1983). The role of products as social stimuli: A symbolic interactionism perspective. Journal of Consumer Research, 10(3), 319-329.

Tenenhaus, M., Vinzi, V., Chatelin, Y., \& Lauro, C. (2005). PLS path modeling. Computacional statistics \& Data Analysis, 48(1), 159-205.

Wetzels, M., Odekerken-Schröder, G., \& van Oppen, C. (2009). Using PLS path modeling for assessing hierarchical construct models: Guidelines and empirical illustration. MIS Quarterly, 33(1), 177-195.

Veblen, T. (1988). A teoria da classe ociosa: um estudo econômico das instituições. São Paulo: Nova Cultural. Veblen, T. (1994). The Theory of the Leisure Class. London: Routledge. 


\section{1 - Lifestyle}

1.1 - Unique lifestyle

I like to experiment with new ways of doing things

I like to take chances

I like to have adventures

\section{2 - Centrality to lifestyle}

I find that a lot of my lifestyle is organized around purchasing costly and branded products I spend too much time engaging myself in purchase experiences

If I stopped engaging in purchase, I would probably lose touch with a lot of my friends

\section{2 - Brand consciousness}

The more expensive brands of products are usually my choice

The higher the price of a product, the better its quality

Nice departments and speciality stores offer me the best products

3 - Conspicuous consumption

3.1 - Ostentation and signaling

I like to try branded products for a wedding occasion

I get attracted toward branded and costly products when buying for a wedding occasion When making purchase for wedding, I am ready to pay more for branded products

\section{2 - Uniqueness}

An important goal is to find brands that communicate my uniqueness during a wedding occasion

I develop my personal uniqueness by buying special brands for wedding occasion

I buy unusual brands for weddings to create a more distinctive personal image

\section{3 - Social conformity}

Branded products purchased for weddings help me feel acceptable

Purchasing branded products for weddings helps me to make a good impression on other people

Buying branded products for weddings gives me social approval

4 - Status consumption

Buying of branded products gives me status symbol for a wedding occasion

Purchase of branded products for weddings indicates wealth to me

Purchase of branded products for weddings indicates sense of achievement to me

To buy branded products for wedding occasion is a symbol of sucess

\section{5 - Self expression}

I like to buy branded products because I want to be socially accepted

I like to buy branded products to be distinctive from others

I like to buy branded products to establish status in society 